\title{
VARIASI GENETIK UJI PROVENAN MERBAU SAMPAI UMUR 3 TAHUN DI BONDOWOSO, JAWA TIMUR
}

\author{
(Genetic Variation of Provenances Test of Merbau until 3 years old in Bondowoso, East Java)
}

Tri Pamungkas Yudohartono dan Burhan Ismail

Balai Besar Penelitian Bioteknologi dan Pemuliaan Tanaman Hutan

E-mail: tyodohartono@yahoo.com

Tanggal diterima: 30 Januari 2012; Direvisi: 2 Maret 2012; Disetujui terbit: 26 Juni 2012

\begin{abstract}
Merbau (Intsia bijuga) is one of high economic value timbers. Establishment of seed source of merbau is essential to supply qualified seeds for plantation. Center for Forest Biotechnology and Tree Improvement has established provenance test of merbau at Sumberwringin Research Forest in Bondowoso, East Java. The objectives of this study are to know survival and genetic variation of growth traits in provenance test plot of merbau. This provenance test was designed as Randomized Complete Block Design with single factor of provenance consisted of Halmahera Timur, Waigo, Oransbari, Wasior, Nabire and Seram. Each provenance comprises 3 blocks as replication and 60 treeplots of each block. The result showed high survival rate of all provenances (above $90 \%$ ). Moreover, genetic variation of height and stem diameter among provenances was also high. The best provenance for survival, and height for all observation years was Wasior. The best provenance for diameter for all observation years was Halmahera Timur. Meanwhile, provenance having the best value of survival, height and diameter for all observation years was Halmahera Timur. The provenance having the worst value of height and diameter for all observation years was Seram. Whereas, the worst provenance of survival at 1, 2 and 3 years old were Waigo, Halmahera Timur dan Seram, respectively.
\end{abstract}

\section{Key words : Intsia bijuga, genetic variation, trait, provenance}

\begin{abstract}
ABSTRAK
Merbau (Intsia bijuga) merupakan salah satu jenis tanaman hutan yang mempunyai nilai ekonomi yang tinggi. Pembangunan sumber benih merbau diperlukan untuk menyediakan benih yang baik untuk penanaman. Balai Besar Penelitian Bioteknologi dan Pemuliaan Tanaman Hutan Yogyakarta telah melakukan pembangunan plot uji provenan jenis merbau di Hutan Penelitian Sumberwringin, Bondowoso, Jawa Timur. Penelitian ini bertujuan untuk mengetahui kemampuan hidup dan keragaman genetik sifat pertumbuhan dari tanaman merbau pada plot uji provenan di Bondowoso, Jawa Timur. Uji provenan merbau dibangun dengan menggunakan Rancangan Acak Lengkap Berblok dengan satu faktor perlakuan yaitu provenan yang meliputi Halmahera Timur, Waigo, Oransbari, Wasior, Nabire dan Seram. Setiap provenan terdiri dari 3 blok. Setiap provenan dalam setiap blok terdiri dari 60 plot tanaman. Hasil penelitian menunjukkan bahwa kemampuan hidup tanaman merbau dari keenam provenan di Bondowoso tergolong baik. Hal ini ditunjukkan dengan tingginya rata-rata persen hidup selama tiga tahun yaitu di atas 90 \%.Keragaman genetik antar provenan untuk sifat pertumbuhan tinggi dan diameter juga tergolong tinggi. Provenan yang paling baik untuk kemampuan hidup, dan tinggi pada semua umur pengamatan adalah provenan Wasior. Provenan yang terbaik untuk sifat diameter semua umur pengamatan adalah provenan Halmahera Timur. Provenan yang paling jelek untuk diameter dan tinggi pada semua umur pengamatan adalah provenan Seram. Provenan yang paling jelek untuk kemampuan hidup pada umur 1, 2 dan 3 tahun masing-masing adalah provenan Waigo, Halmahera Timur dan Seram.
\end{abstract}

Kata-kata kunci : Intsia bijuga, variasi genetik, sifat, provenan 


\section{PENDAHULUAN}

Merbau (Intsia bijuga) merupakan salah satu jenis tanaman yang banyak dimanfaatkan dan mempunyai nilai ekonomi yang tinggi karena sudah sangat dikenal dalam perdagangan kayu di Indonesia maupun untuk keperluan ekspor. Jenis ini dapat tumbuh hingga ketinggian $1000 \mathrm{~m}$ dpl pada berbagai jenis tanah kecuali tanah gambut dengan curah hujan lebih dari 2000mm/tahun dan menjadi salah satu jenis pohon tropis di Indonesia yang diprioritaskan untuk program konservasi genetik dan pemuliaan. Wilayah penyebaran Intsia bijuga meliputi Samoa (Amerika), Australia, Burma, Kamboja, India, Indonesia, Madagaskar bagian barat (pada daerah rendah), Malaysia, Myanmar, Pulau-pulau Pasifik, Papua New Guinea, Philipina, Seychelles, Tanzania, Thailand dan Vietnam (TCIS, 2007). Permintaan kayu merbau cenderung mengalami peningkatan. Ekspor kayu merbau Indonesia berturut-turut dari tahun 1990, 1991 dan 1992 yaitu sebesar $1.700 \mathrm{~m}^{3}, 17.000 \mathrm{~m}^{3}$ dan 137.000 $\mathrm{m}^{3}$. Pemenuhan kebutuhan kayu merbau masih dilakukan dari penebangan hutan alam sampai saat ini, sehingga populasinya semakin menurun. Apabila eksploitasi jenis ini terus dilakukan tanpa diimbangi dengan upaya penanaman yang memadai, maka ke depan dikhawatirkan populasi merbau akan semakin menurun. Berdasarkan kategori IUCN Red List (1994) status konservasi merbau sudah termasuk kategori rawan (VU A1cd). Penurunan populasi tersebut dapat mengakibatkan berkurangnya keragaman genetik merbau. Keragaman genetik yang tinggi sangat penting bagi program pemuliaan karena optimalisasi perolehan genetik akan dapat dicapai dengan semakin besarnya peluang untuk seleksi terhadap sifatsifat yang diinginkan.

Upaya penanaman dan pembangunan hutan tanaman menjadi salah satu solusi untuk meminimalisasi tekanan terhadap populasi alam merbau untuk pemenuhan bahan baku industri. Pembangunan sumber benih merbau diperlukan untuk menyediakan benih yang baik untuk penanaman. Balai Besar Penelitian Bioteknologi dan Pemuliaan Tanaman Hutan Yogyakarta telah melakukan pembangunan plot uji provenan jenis merbau di Hutan Penelitian Sumberwringin, Bondowoso, Jawa Timur. Materi genetik yang digunakan untuk pembangunan plot uji provenan merbau tersebut berasal dari enam populasi yang berbeda. Keenam populasi tersebut adalah Halmahera Timur, Waigo, Oransbari, Wasior, Nabire dan Seram (Mahfudz, dkk., 2006). Keberhasilan program pemuliaan tanaman dipengaruhi penggunaan sumber benih dan provenan yang tepat. Jenis tanaman yang memiliki perbedaan ras geografis yang terbesar akan mempunyai peluang yang paling baik dalam perolehan genetik melalui seleksi provenan. Karakteristik yang menentukan perbedaan antar ras geografis 
lebih dominan karakter fisiologis dibanding karakter morfologi. Oleh karena itu perlu dilakukan pengujian antar provenan karena perbedaan karakter fisiologis akan mempengaruhi kemampuan hidup dan pertumbuhan tanaman. Perbedaan antar provenan yang disebabkan oleh beberapa faktor dapat mengakibatkan perbedaan kompleks gen yang dapat berdampak pada perbedaan pertumbuhan dan kemampuan bertahan hidup pada kondisi lingkungan tertentu (Zobel \& Talbert, 1984). Beberapa faktor yang mempengaruhi variabilitas provenan antara lain ukuran penyebaran spesies, perbedaan (diversitas) tempat tumbuh pada distribusi alaminya dan kontinyuitas penyebaran. Plot uji provenan merbau ini nantinya diharapkan dapat dimanfaatkan sebagai plot konservasi ex situ yang akan mendukung atau dapat dimanfaatkan untuk kegiatan pemuliaan pohon di masa sekarang dan akan datang. Penelitian ini bertujuan untuk mengetahui kemampuan hidup dan keragaman genetik sifat pertumbuhan dari tanaman merbau pada plot uji provenan di Bondowoso, Jawa Timur.

\section{BAHAN DAN METODE}

\section{A. Lokasi Penelitian}

Kegiatan penelitian dilakukan pada plot uji provenan merbau di Hutan Penelitian Sumberwringin, Bondowoso. Hutan Penelitian Sumberwringin Bondowoso secara administratif terletak di Desa Wringinanom, Kecamatan Sukosari, Kabupaten Bondowoso, Propinsi Jawa Timur. Menurut klasifikasi iklim Schmidt dan Ferguson, Hutan Penelitian Sumberwringin termasuk iklim B dengan curah hujan 2400 $\mathrm{mm} /$ tahun, hari hujan terbanyak bulan Januari dan menurun mulai bulan Juni. Jenis tanahnya adalah asosiasi andosol coklat, kelerengan berkisar antara 0 - $15 \%$ dan merupakan fisiografi dataran dengan ketinggian $\pm 800 \mathrm{~m}$ di atas permukaan laut. Tumbuhan penutup tanah yang banyak dijumpai di dalam plot penelitian adalah semak dan alang-alang (РPPBPTH, 2004). Pengukuran tanaman merbau dilakukan pada tahun 2007, 2008 dan 2009.

\section{B.Bahan Penelitian}

Bahan yang digunakan dalam penelitian ini adalah tanaman merbau pada plot plot uji provenan merbau di Hutan Penelitian Sumberwringin, Bondowoso. Plot tersebut dibangun pada tahun 2006. Desain penelitian yang digunakan dalam plot uji provenan merbau adalah Rancangan Acak Lengkap Berblok (Randomized Complete Block Design) dengan satu faktor perlakuan yaitu asal bibit/provenan. Provenan yang digunakan adalah Halmahera Timur, Waigo, Oransbari, Wasior, Nabire dan Seram. Setiap provenan terdiri dari 3 blok yang sekaligus berfungsi sebagai ulangan. Setiap provenan dalam setiap blok terdiri dari 60 tanaman. Plot berbentuk persegi panjang dengan 
ukuran 5 x 15. Jarak tanam yang digunakan pada plot uji provenan adalah 3 x $3 \mathrm{~m}$. Luas plot uji provenan merbau adalah 2,5 ha (Mahfudz, dkk., 2006). Deskripsi dari setiap provenan disajikan pada Tabel 1.

Tabel 1. Populasi merbau yang digunakan dalam penelitian

\begin{tabular}{|c|l|l|l|}
\hline No & \multicolumn{1}{|c|}{ Populasi } & \multicolumn{1}{|c|}{ Koordinat } & $\begin{array}{c}\text { Ketinggian } \\
\text { tempat } \\
(\mathrm{m} \mathrm{dpl})\end{array}$ \\
\hline 1 & Halmahera Timur & $0^{\circ} 48^{\prime} \mathrm{LU}$ dan $127^{\circ} 52^{\prime} \mathrm{BT}$ & $50-200$ \\
\hline 2 & Waigo & $1^{\circ} 23^{\prime} \mathrm{LS}$ dan $131^{\circ} 58^{\prime} \mathrm{BT}$ & $50-200$ \\
\hline 3 & Oransbari & $1^{\circ} 19^{\prime} \mathrm{LS}$ dan $134^{\circ} 15^{\prime} \mathrm{BT}$ & $50-200$ \\
\hline 4 & Wasior & $2^{\circ} 31^{\prime} \mathrm{LS}$ dan $134^{\circ} 32^{\prime} \mathrm{BT}$ & $200-500$ \\
\hline 5 & Nabire & $3^{\circ} 38^{\prime} \mathrm{LS}$ dan $135^{\circ} 13^{\prime} \mathrm{BT}$ & $200-500$ \\
\hline 6 & Seram & $2^{0} 55^{\prime} \mathrm{LS}$ dan $128^{\circ} 48^{\prime} \mathrm{BT}$ & $200-500$ \\
\hline
\end{tabular}

\section{Karakter yang diukur}

Karakter atau sifat pertumbuhan diukur pada seluruh tanaman merbau pada plot uji provenan. Kegiatan ini dilakukan pada umur 1, 2 dan 3 tahun. Sifat pertumbuhan yang diukur adalah tinggi dan diameter tanaman. Tinggi pohon diukur dari permukaan tanah sampai titik tumbuh apikal (ujung tanaman). Diameter batang diukur pada ketinggian $10 \mathrm{~cm}$ di atas permukaan tanah. Di samping itu persen hidup tanaman juga dievaluasi.

\section{Analisis Data}

Data hasil pengukuran dianalisis dengan menggunakan analisis varian untuk mengetahui variasi antar provenan. Apabila terdapat variasi antar provenan yang diuji, maka dilanjutkan dengan Uji Jarak Berganda Duncan (Duncan's
Multiple Range Test-DMRT) untuk melihat perbedaan antar provenan yang diuji.

Model matematis yang digunakan adalah:

$$
\mathbf{Y}_{\mathrm{ij}}=\boldsymbol{\mu}+\mathbf{B}_{\mathrm{i}}+\mathbf{P}_{\mathbf{j}}+\varepsilon_{\mathrm{ij}}
$$

dimana :

$\mathrm{Y}_{\mathrm{ij}} \quad=$ Karakteristik yang diamati/diukur

$\mu \quad=$ Rerata umum

$\mathrm{P}_{\mathrm{j}} \quad=$ Pengaruh provenan ke-j

$\mathrm{B}_{\mathrm{i}} \quad=$ Efek blok ke-i

$\varepsilon_{\mathrm{ij}} \quad=$ Random error pada pengamatan ke-ij

\section{HASIL DAN PEMBAHASAN}

\section{A. Hasil}

\section{Persen hidup}

Hasil terhadap persen hidup tanaman merbau pada pada plot uji provenan di Bondowoso pada umur 1, 2 dan 3 tahun disajikan pada Tabel 2.

\section{Diameter}

Untuk mengetahui variasi antar provenan untuk sifat diameter maka dilakukan analisis varian terhadap data pengukuran diameter. Hasil analisis varian untuk sifat diameter disajikan pada Tabel 3. Pada Tabel 3 terlihat bahwa terdapat perbedaan yang nyata antar provenan untuk sifat diameter pada umur 1, 2 dan 3 tahun. Perbedaan yang sangat nyata menunjukkan adanya keragaman/variasi genetik yang tinggi dari karakteristik atau sifat diameter. Perbedaan dan ranking provenan dapat dilihat dengan menggunakan Uji Jarak Berganda Duncan yang hasilnya disajikan pada Tabel 4. 
Tabel 2. Persen hidup tanaman merbau pada plot uji provenan di Bondowoso pada umur 1,2 dan 3 tahun

\begin{tabular}{|c|c|c|c|c|c|c|}
\hline \multirow{2}{*}{ Tahun } & \multicolumn{7}{|c|}{ Persen hidup (\%) tiap Populasi } \\
\cline { 2 - 8 } & Halmahera Timur & Waigo & Oransbari & Wasior & Nabire & Seram \\
\hline Tahun 1 & 98,33 & 96,11 & 97,22 & 100,00 & 98,33 & 97,72 \\
\hline Tahun 2 & 88,33 & 90,00 & 90,56 & 93,89 & 93,33 & 88,58 \\
\hline Tahun 3 & 87,22 & 89,44 & 88,33 & 92,22 & 87,22 & 84,47 \\
\hline
\end{tabular}

Tabel 3. Analisis varian untuk sifat diameter tanaman merbau pada plot uji provenan di Bondowoso pada umur 1,2 dan 3 tahun

\begin{tabular}{|l|c|c|c|c|c|}
\hline \multicolumn{7}{|c|}{ Umur 1 Tahun } \\
\hline $\begin{array}{c}\text { Sumber } \\
\text { Variasi }\end{array}$ & $\begin{array}{c}\text { Derajad } \\
\text { bebas }\end{array}$ & $\begin{array}{c}\text { Jumlah } \\
\text { kuadrat }\end{array}$ & $\begin{array}{c}\text { Kuadrat } \\
\text { tengah }\end{array}$ & F & Sig \\
\hline Provenan & 5 & 22,08 & 4,42 & $17,47^{* *}$ & 0,000 \\
\hline Blok & 2 & 1,21 & 0,60 & $2,38 \mathrm{~ns}$ & 0,142 \\
\hline Error & 10 & 2,53 & 0,25 & & \\
\hline \multicolumn{7}{|c|}{ Umur 2 Tahun } \\
\hline $\begin{array}{c}\text { Sumber } \\
\text { Variasi }\end{array}$ & $\begin{array}{c}\text { Derajad } \\
\text { bebas }\end{array}$ & $\begin{array}{c}\text { Jumlah } \\
\text { kuadrat }\end{array}$ & $\begin{array}{c}\text { Kuadrat } \\
\text { tengah }\end{array}$ & F & Sig \\
\hline Provenan & 5 & 55,32 & 11,06 & $8,38^{* *}$ & 0,002 \\
\hline Blok & 2 & 1,48 & 0,74 & $0,56^{\text {ns }}$ & 0,590 \\
\hline Error & 10 & 13,20 & 1,32 & & \\
\hline \multicolumn{7}{|c|}{ Umur 3 Tahun } \\
\hline $\begin{array}{l}\text { Sumber } \\
\text { Variasi }\end{array}$ & $\begin{array}{c}\text { Derajad } \\
\text { bebas }\end{array}$ & $\begin{array}{c}\text { Jumlah } \\
\text { kuadrat }\end{array}$ & $\begin{array}{c}\text { Kuadrat } \\
\text { tengah }\end{array}$ & F & Sig \\
\hline Provenan & 5 & 256,10 & 51,22 & $4,59^{*}$ & 0,020 \\
\hline Blok & 2 & 36,76 & 18,38 & 1,65 & 0,241 \\
\hline Error & 10 & 111,56 & 11,16 & & \\
\hline
\end{tabular}

Keterangan $\quad * *=$ berbeda nyata pada taraf uji $1 \%$

* = berbeda nyata pada taraf uji $5 \%$

Tabel 4. Hasil Uji Jarak Berganda Duncan untuk sifat diameter tanaman merbau pada plot uji provenan di Bondowoso pada umur 1, 2 dan 3 tahun

\begin{tabular}{|c|l|l|l|l||}
\hline No & \multirow{2}{*}{ Populasi } & \multicolumn{3}{|c|}{ Diameter $(\mathbf{m m})$} \\
\cline { 3 - 5 } & & Tahun 1 & \multicolumn{1}{|c|}{ Tahun 2} & Tahun 3 \\
\hline 1 & Halmahera Timur & $10,26 \mathrm{~b}$ & $14,61 \mathrm{c}$ & $25,82 \mathrm{c}$ \\
\hline 2 & Waigo & $9,68 \mathrm{~b}$ & $13,64 \mathrm{bc}$ & $23,75 \mathrm{bc}$ \\
\hline 3 & Oransbari & $9,83 \mathrm{~b}$ & $13,31 \mathrm{bc}$ & $21,98 \mathrm{bc}$ \\
\hline 4 & Wasior & $10,19 \mathrm{~b}$ & $13,97 \mathrm{bc}$ & $23,92 \mathrm{bc}$ \\
\hline 5 & Nabire & $9,49 \mathrm{~b}$ & $12,02 \mathrm{~b}$ & $18,21 \mathrm{ab}$ \\
\hline 6 & Seram & $7,00 \mathrm{a}$ & $9,03 \mathrm{a}$ & $14,81 \mathrm{a}$ \\
\hline \hline
\end{tabular}

\section{Tinggi}

Untuk mengetahui variasi antar provenan untuk sifat tinggi maka dilakukan analisis varian terhadap data pengukuran diameter. Hasil analisis varian untuk sifat tinggi pada umur 1, 2, dan 3 tahun disajikan pada Tabel 5.

Tabel 5. Analisis varian untuk sifat tinggi tanaman merbau pada plot uji provenan di Bondowoso pada umur 1,2 dan 3 tahun

\begin{tabular}{|l|c|c|c|c|c|}
\hline \multicolumn{7}{|c|}{ Umur 1 Tahun } \\
\hline $\begin{array}{c}\text { Sumber } \\
\text { Variasi }\end{array}$ & $\begin{array}{c}\text { Derajad } \\
\text { bebas }\end{array}$ & $\begin{array}{c}\text { Jumlah } \\
\text { kuadrat }\end{array}$ & $\begin{array}{c}\text { Kuadrat } \\
\text { tengah }\end{array}$ & F & Sig \\
\hline Provenan & 5 & 3506,23 & 701,25 & $101,29^{* *}$ & 0,000 \\
\hline Blok & 2 & 207,00 & 103,50 & $14,95^{* *}$ & 0,001 \\
\hline Error & 10 & 69,23 & 6,92 & & \\
\hline \multicolumn{7}{|c|}{ Umur 2 Tahun } \\
\hline $\begin{array}{l}\text { Sumber } \\
\text { Variasi }\end{array}$ & $\begin{array}{c}\text { Derajad } \\
\text { bebas }\end{array}$ & $\begin{array}{c}\text { Jumlah } \\
\text { kuadrat }\end{array}$ & $\begin{array}{c}\text { Kuadrat } \\
\text { tengah }\end{array}$ & F & Sig \\
\hline Provenan & 5 & 4576,67 & 915,33 & $27,00^{* *}$ & 0,000 \\
\hline Blok & 2 & 63,94 & 318,47 & $9,40^{* *}$ & 0,005 \\
\hline Error & 10 & 338,97 & 33,89 & & \\
\hline \multicolumn{7}{|c|}{ Umur 3 Tahun } \\
\hline $\begin{array}{l}\text { Sumber } \\
\text { Variasi }\end{array}$ & $\begin{array}{c}\text { Derajad } \\
\text { bebas }\end{array}$ & $\begin{array}{c}\text { Jumlah } \\
\text { kuadrat }\end{array}$ & $\begin{array}{c}\text { Kuadrat } \\
\text { tengah }\end{array}$ & F & Sig \\
\hline Provenan & 5 & 11441,00 & 2288,20 & $5,18^{*}$ & 0,013 \\
\hline Blok & 2 & 2563,41 & 1281,71 & 2,90 ns & 0,102 \\
\hline Error & 10 & 4419,08 & 441,91 & & \\
\hline
\end{tabular}

Keterangan $\quad * *=$ berbeda nyata pada taraf uji $1 \%$

$$
\text { * = berbeda nyata pada taraf uji } 5 \%
$$

Pada Tabel 5 terlihat bahwa terdapat perbedaan yang nyata antar provenan untuk sifat tinggi pada umur 1, 2 dan 3 tahun. Perbedaan yang sangat nyata menunjukkan adanya keragaman/variasi genetik yang tinggi dari karakteristik atau sifat tinggi. Perbedaan dan ranking provenan dapat dilihat dengan menggunakan Uji Jarak Berganda Duncan yang hasilnya disajikan pada Tabel 6. 
Tabel 6. Hasil Uji Jarak Berganda Duncan untuk sifat tinggi tanaman merbau pada plot uji provenan di Bondowoso pada umur 1,2 dan 3 tahun

\begin{tabular}{|c|l|l|l|l||}
\hline No & \multirow{2}{*}{ Populasi } & \multicolumn{3}{|c|}{ Tinggi (cm) } \\
\cline { 3 - 5 } & & Tahun 1 & Tahun 2 & Tahun 3 \\
\hline 1 & Halmahera Timur & $75,72 \mathrm{~b}$ & $96,41 \mathrm{~b}$ & $165,23 \mathrm{~b}$ \\
\hline 2 & Waigo & $87,77 \mathrm{de}$ & $102,89 \mathrm{bc}$ & $163,57 \mathrm{~b}$ \\
\hline 3 & Oransbari & $80,7 \mathrm{c}$ & $96,86 \mathrm{~b}$ & $148,65 \mathrm{~b}$ \\
\hline 4 & Wasior & $91,83 \mathrm{e}$ & $110,55 \mathrm{c}$ & $167,45 \mathrm{~b}$ \\
\hline 5 & Nabire & $83,17 \mathrm{~cd}$ & $94,21 \mathrm{~b}$ & $129,69 \mathrm{ab}$ \\
\hline 6 & Seram & $48,97 \mathrm{a}$ & $59,93 \mathrm{a}$ & $96,96 \mathrm{a}$ \\
\hline
\end{tabular}

\section{B. Pembahasan}

Rata-rata persen hidup dari masing-masing provenan merbau selama tiga tahun tergolong tinggi yaitu diatas $90 \%$. Tingginya persen hidup ini mengindikasikan bahwa tanaman merbau dari keenam provenan tersebut dapat beradaptasi dengan baik pada plot uji provenan di Bondowoso. Rata-rata persen hidup diatas 90 \% merupakan indikator yang baik dalam pertanaman uji (Na'iem, 2004). Hal ini disebabkan karena kondisi lingkungan di plot uji provenen merbau tersebut memenuhi kriteria persyaratan tumbuh merbau. Pada sebaran alaminya merbau dijumpai tumbuh hingga ketinggian $1000 \mathrm{~m}$ dpl pada berbagai jenis tanah kecuali tanah gambut dengan curah hujan lebih dari $2000 \mathrm{~mm} /$ tahun. Plot uji provenan merbau di Bondowoso terletak pada ketinggian $800 \mathrm{~m}$ dpl dengan curah hujan 2400 mm/tahun. Persen hidup tanaman merbau bervariasi antar populasi pada semua umur pengamatan. Persen hidup tanaman merbau tertinggi pada plot uji provenan di Bondowoso pada umur1, 2 dan 3 tahun dicapai populasi/provenan yang sama yaitu Wasior. Persen hidup tanaman merbau terendah pada plot uji provenan di Bondowoso pada umur 1, 2 dan 3 tahun masing-masing dicapai populasi/provenan yang berbeda yaitu Waigo, Halmahera Timur dan Seram.

Ranking terbaik untuk sifat diameter secara konsisten dicapai oleh provenan yang sama yaitu provenan Halmahera Timur. Demikian juga dengan ranking terendah untuk sifat diameter juga dicapai oleh provenan yang sama yaitu provenan Seram. Sedangkan untuk sifat tinggi, ranking terbaik pada umur 1, 2 dan 3 tahun secara konsisten dicapai provenan yang sama yaitu provenan Wasior. Ranking terendah untuk sifat tinggi pada umur 1, 2 dan 3 tahun secara konsisten dicapai oleh provenan Seram. Meskipun ada kecenderungan pada konsitensi ranking terbaik dan terendah terutama pada sifat pertumbuhan tinggi dan diameter tetapi urutan rangking masih bervariasi atau belum konsisten. Hal ini diduga dipengaruhi kondisi penutupan lahan yang berbeda antar blok plot uji provenan yang diamati. Pada plot uji provenan merbau di Hutan Penelitian Sumberwringin Bondowoso kondisi penutupan tanah dan naungan pada setiap blok berbeda-beda. Pada blok pertama penutupan tanah berupa rerumputan dan beberapa pohon petai, blok kedua penutupan tanah berupa rerumputan dan semak belukar tanpa pepohonan dan blok ketiga penutupan tanah berupa rerumputan, semak belukar dan 
tegakan cemara yang cukup rapat. Perbedaan penutupan tanah tersebut menyebabkan terjadinya perbedaan intensitas cahaya dan kompetisi tanaman merbau dan gulma dalam mengambil air, dan unsur hara dalam tanah yang pada akhirnya mempengaruhi kemampuan hidup dan pertumbuhan tanaman merbau.

Adanya variasi sifat pertumbuhan antar provenan dan belum konsitensinya ranking provenan pada plot uji juga ditemukan pada penelitian jenis lain. Hadiyan (2010) menyatakan bahwa pada plot uji keturunan sengon umur 6 bulan pertumbuhan tinggi dan diameter terbaik sengon berasal dari sumber benih Kediri. Tetapi pada umur 1 tahun ranking pertumbuhan ini berubah dan yang terbaik berasal dari sumber benih Candiroto dan Lombok untuk diameter dan Wamena untuk tinggi tanaman. Berdasarkan hasil penelitian Susanto (2010) diketahui bahwa terdapat perbedaan yang signifikan untuk tinggi dan diameter pada plot uji provenan ulin umur 3 tahun di Hutan Penelitian Sumberwringin Bondowoso. Tetapi berdasarkan hasil uji Duncan terdapat perbedaan dalam pengelompokan populasi berdasarkan sifat tinggi dan diameter. Dari keempat populasi yang diamati untuk sifat tinggi populasi ulin dibagi ke dalam dua kelomok sedangkan untuk sifat diameter dibagi kedalam empat kelompok. Untuk mengetahui konsistensi peran variasi genetik antar provenan yang diuji terhadap kemampuan hidup dan karakter pertumbuhan tanaman merbau pada plot uji maka perlu dilakukan pengukuran dan pengamatan karakter pertumbuhan dan karakter-karakter lainnya pada tahun-tahun berikutnya.

Sementara itu, berdasarkan jarak genetik Nei (1972) diketahui bahwa pasangan populasi/provenan yang mempunyai jarak genetik terbesar dan terkecil masing-masing adalah Halmahera Timur-Seram dan NabireOransbari. Nilai ini mengindikasikan bahwa populasi Nabire dan Oransbari mempunyai hubungan kekerabatan yang paling dekat. Sedangkan populasi Halmahera Timur dan Seram mempunyai hubungan kekerabatan yang paling jauh (Yudohartono, 2009). Kondisi ini sejalan dengan hasil pengukuran pada karakter pertumbuhan tanaman merbau. Populasi Halmahera Timur dan Seram yang memiliki hubungan kekerabatan paling jauh ternyata juga mempunyai perbedaan nilai rata-rata diameter tertinggi dibandingkan pasangan provenan yang lain. Berdasarkan nilai rata-rata tinggi juga diketahui bahwa perbedaan nilai rata-rata tinggi antara provenan Halmahera Timur dan Seram semakin tinggi dengan bertambahnya usia tanaman merbau. Sementara itu, perbedaan nilai rata-rata diameter dan tinggi antara provenan Nabire dan Oransbari tidak terlalu jauh. Menurut Loveless dan Hamrick (1984), diferensiasi genetik antar populasi dipengaruhi oleh adanya aliran gen melalui penyebaran 
serbuk sari dan biji. Spesies dengan populasi diskontinyu dan terisolasi menunjukkan kenaikan tingkat diferensiasi genetik karena turunnya aliran gen. Perbedaan struktur genetik tersebut dapat diekspresikan melalui perbedaan karakteristik tanaman. Disamping itu berdasarkan hasil uji Duncan juga diketahui bahwa populasi Seram membentuk kelompok tersendiri dan terpisah dari provenan lain. Hal ini sejalan dengan hasil penelitian Yudohartono (2008) yang menyatakan bahwa berdasarkan analisis klaster UPGMA populasi Seram juga membentuk satu klaster tersendiri dan terpisah dari klaster-klaster yang lain. Pulau Seram yang terlepas jauh terlebih dahulu dan dipisahkan oleh lautan mengalami isolasi reproduksi dan adaptasi lokal terhadap lingkungan setempat yang menyebabkan semakin meningkatnya diferensiasi genetik antara populasi merbau di Seram dan populasi-populasi merbau dari Halmahera dan Papua. Seram merupakan populasi/provenan yang unik karena pada lokus tertentu ada alel yang hanya dimiliki populasi Seram dan tidak dimiliki oleh kelima populasi yang lain.

Berdasarkan Tabel 3 dan 5 dapat diketahui bahwa terdapat perbedaan yang sangat nyata diantara keenam provenan yang diuji untuk sifat/karakter pertumbuhan diameter dan tinggi tanaman merbau pada plot konservasi ex situ di Bondowoso pada umur 1, 2 dan 3 tahun. Hal ini mengindikasikan bahwa diantara provenan tersebut terdapat variasi genetik yang tinggi yang memberikan pengaruh pada sifat pertumbuhan diameter dan tinggi. Menurut Yudohartono (2008), rata-rata keragaman genetik I. bijuga dari keenam populasi merbau (Halmahera Timur, Waigo, Oransbari, Wasior, Nabire dan Seram) adalah 0,392. Rata-rata keragaman genetik I. bijuga ini juga lebih tinggi dibandingkan keragaman genetik $I$. palembanica yakni sebesar 0,242 ( Lee, dkk., 2002), semua jenis $(0,113)$, tanaman tropis $(0,211)$ dan tanaman kayu berumur panjang $(0,149)$ (Hamrick, Godt, Murawski dan Loveless, 1991). Keragaman genetik sangat penting karena merupakan faktor utama yang memungkinkan suatu populasi mampu beradaptasi terhadap perubahan lingkungan, evolusi jangka panjang dan menjadi pondasi untuk pemuliaan genetik (Lande and Shannon, 1996 dalam Rimbawanto dan Widyatmoko, 2006). Menurut Zobel \& Talbert (1984), suatu jenis pohon yang memiliki daerah penyebaran alam luas akan didapati keragaman geografis yang menyebabkan jenis tersebut dapat dipisahkan rnenjadi sub populasi-sub populasi yang berbeda yang dikenal dengan ras-ras geografis. Oleh karena keenam populasi merbau yang diamati berasal dari tempat yang berbeda secara geografis dan kondisi tempat tumbuh maka keragaman genetiknya tinggi. Adaptasi lokal yang telah berlangsung dalam waktu yang lama ini diduga dapat menyebabkan terjadinya 
perbedaan struktur genetik antar populasi tersebut. Menurut Zobel, et.al (1976) kebanyakan jenis tanaman hutan mempunyai satu sampai beberapa provenan yang memiliki sifat genetik penting yang bersifat unik satu sama lain dan sebaliknya. Oleh karena itu, pekerjaan besar pertama dalam konservasi kompleks gen bagi para pemulia tanaman adalah menyelamatkan sifat yang unik dari suatu provenan. Dengan adanya variasi genetik yang tinggi antar populasi/provenan merbau pada plot uji provenan merbau di Bondowoso maka semakin besar juga potensi dari sumber daya genetik merbau yang bisa diselamatkan dan dimanfaatkan untuk mendukung program pemuliaan jenis merbau.

\section{KESIMPULAN}

1. Kemampuan hidup tanaman merbau dari keenam provenan pada plot uji provenan di Bondowoso tergolong baik. Hal ini ditunjukkan dengan tingginya rata-rata persen hidup selama tiga tahun yaitu diatas $90 \%$.

2. Di antara keenam provenan yang diamati terdapat variasi genetik yang tinggi yang memberikan pengaruh pada sifat pertumbuhan diameter dan tinggi. Provenan yang paling baik untuk kemampuan hidup, dan tinggi pada semua umur pengamatan adalah provenan Wasior. Provenan yang terbaik untuk sifat diameter pada semua umur pengamatan adalah provenan Halmahera Timur. Sebaliknya, Seram merupakan provenan yang memiliki pertumbuhan diameter dan tinggi yang paling lambat pada semua umur pengamatan. Sedangkan provenan kemampuan hidup paling rendah pada umur 1,2 dan 3 tahun masing-masing adalah Waigo, Halmahera Timur dan Seram.

\section{DAFTAR PUSTAKA}

Cossalter, C. 1989. Genetic conservation : a cornerstone of breeding strategies. In Gibson, G.L., Griffin, A.R. and Matheson, A.C. (eds). pp. 28-38.

Hadiyan, Y. 2010. Pertumbuhan dan Parameter Genetik Uji Tanaman Sengon (Falcataria moluccana) di Cikampek Jawa Barat. Jurnal Pemuliaan Tanaman Hutan Vol. 4 No.2, September 2010. Balai Besar Penelitian Bioteknologi dan Pemuliaan Tanaman Hutan. Badan Penelitian dan Pengembangan Kehutanan, Departemen Kehutanan

Hamrick, J.L., Godt, M.J.W., Murawki, D.A. and Loveless, M.D. 1991. Correlation between species traits and allozyme diversity : implications for conservation biology. In A.D. Falk and K.E. Holsinger (eds). Genetics and conservation of rare plants, 75-83. Oxford University Press, New York, USA.

IUCN. 1994. IUCN Red List Categories. Prepared by the IUCN Species Survival Commission. IUCN, Gland, Switzerland.

Lee, S.L., Kevin, K.S., Leng-Guan S., Adnan N., Siti S.,, Chai-Ting L., and Muhammad N. 2002. Population genetics of Intsia palembanica (Leguminosae) and genetic conservation of virgin jungle reserve in Peninsular Malaysia. American Journal of Botany 89 (3): 447-459.

Loveless, M.D. and Hamrick, J.L. 1984. Ecological Determinant Genetic Structure in Plant Population. Ann. Rev.Ecol.Syst. 15 : 65-95.

Mahfudz, Yudohartono, T.P., dan Sugeng, P. 2006. Pembangunan Kebun Konservasi Jenis Merbau (Intsia spp). Laporan Akhir. Puslitbang Bioteknologi dan Pemuliaan tanaman Hutan. Yogyakarta.

Na'iem, M. 2004. Uji genetik sebagai elemen dasar kegiatan pemuliaan pohon dalam Dari Bukit-bukit 
Gundul sampai ke Wanagama I. Yayasan Sarana Wanajaya, Jakarta.

PPPBPTH (Pusat Penelitian dan Pengembangan Bioteknologi dan Pemuliaan Tanaman Hutan). 2004. Sekilas Tentang Hutan Penelitian Sumberwringin Bondowoso. Yogyakarta.

Rimbawanto, A. danWidyatmoko, A.Y.P.B.C. 2006 Keragaman genetik empat populasi Intsia bijuga berdasarkan penanda RAPD dan implikasinya bagi program konservasi genetik. Jurnal Penelitian Hutan Tanaman Vol. 3 No.3, Juni 2006. Pusat Penelitian dan Pengembangan Hutan Tanaman. Badan Penelitian dan Pengembangan Kehutanan, Departemen Kehutanan.

Susanto, M. 2010. Variasi Genetik Pertumbuhan pada Plot Uji Provenan dan Uji Keturunan Eusideroxylon zwagery di Bondowoso, Jawa Timur. Jurnal Pemuliaan Tanaman Hutan Vol. 4 No.3, November 2010. Balai Besar Penelitian Bioteknologi dan Pemuliaan Tanaman Hutan. Badan Penelitian dan Pengembangan Kehutanan, Departemen Kehutanan.

TCIS. 2007. Intsia bijuga. http://www.unep-wcmc.org /trees/trade/int_bij.htm Diakses pada tanggal 04 Desember 2008.

Yudohartono, T.P. 2008. Studi Variasi Genetik Beberapa Populasi Merbau (Intsia Bijuga O.Ktze) Menggunakan Penanda Isoenzim dan Pemanfaatannya dalam Program Konservasi Genetik. Tesis Program Studi Ilmu Kehutanan Jurusan, Fakultas Kehutanan, Universitas Gadjah Mada, Yogyakarta.

Yudohartono, T.P. 2008. Variasi Genetik Beberapa Populasi Merbau (Intsia Bijuga O.Ktze) Berdasarkan Penanda Isoenzim. Jurnal Pemuliaan Tanaman Hutan Vol. 2 No.3, November 2008. Balai Besar Penelitian Bioteknologi dan Pemuliaan Tanaman Hutan. Badan Penelitian dan Pengembangan Kehutanan, Departemen Kehutanan.

Zobel, B., Mc.Kee, A., Hoek, G.M., and Dyrness, C. 1976. Relationship of environment to composition, structure and diversity of forest communities of the central western carcades of Oregon. Ecol.Mono. 46: 135-156.

Zobel, B ., and Tabert, J. 1984. Applied forest Tree Improvement. Waveland Press Inc. John Wiley \&Son, Inc, New York. 